\title{
Fibrinogen Sevilla, a congenital dysfibrinogenemia characterized by an abnormal monomer aggregation and a defective plasmin lysis
}

\author{
Francisco J. Fernández ${ }^{1}$, P. Noguerol ${ }^{2}$, R. Sosa ${ }^{2}$, Braulia Cuesta ${ }^{1}$, \\ José A. Páramo ${ }^{1}$ and Eduardo Rocha ${ }^{1}$ \\ ${ }^{\prime}$ Hematology Services, University Clinic of Navarra, Faculty of Medicine, University of Navarra, Pamplona \\ and ${ }^{2}$ Children's Hospital of C.S. Virgen del Rocio, Sevilla (Spain)
}

(Received 19 March 1988; revision received 30 September 1988; accepted 10 October 1988)

Key words: Fibrinogen; Dysfibrinogenemia; Chromatofocussing; Agarose gel isoelectrofocussing

\section{Summary}

A dysfibrinogenemia (fibrinogen Sevilla) was detected in a 64-yr-old woman with no previous history of hemorrhagic diathesis or thrombosis. Thrombin and reptilase times were prolonged. The aggregation of fibrin monomers showed a prolonged latency time with a defective slope although fibrinopeptide release and clot stabilization were found to be normal. Plasmin proteolysis was abnormal with a much slower plasmic degradation in patient's purified fibrinogen. By chromatofocussing the patient's fibrinogen showed an abnormality in pattern elution with a second peak eluting at a $\mathrm{pH}$ slightly more basic than the normal one (pH 5.5). Likewise, the isoelectrofocussing of purified non-reduced patient's fibrinogen in agarose gel showed an abnormal distribution in its focussed bands, especially in a group which focussed in a pI-interval between 5.20-5.85. By two-dimensional electrophoresis we did not find any abnormality in the fibrinogen-reduced chains. These results could indicate that the abnormal monomer aggregation, as well as the defective plasmin lysis, could be due to conformational aspects of fibrinogen rather than to structural defects.

\section{Introduction}

The term dysfibrinogenemia describes the presence in plasma of an abnormal functional fibrinogen. Since the first description of a dysfibrinogenemia [1], the

Correspondence to: Francisco J. Fernández, University Clinic of Navarra, Faculty of Medicine, Apartado 192, 31080 Pamplona, Spain. 
number of reports of this abnormality have increased steadily [2]. In the majority of cases the basic molecular defect is unknown or has yet to be clearly established. Dysfibrinogenemias in which the molecular defect has been reported are associated with an aminoacid substitution which could affect any of the three chains [2].

In this study, we present a further variant of congenital dysfibrinogenemia which is characterized mainly by an anomalous monomer aggregation and a slower fibrinogen proteolysis by plasmin.

\section{Case report, materials and methods}

The propositus was a 64-yr-old Spanish female with no previous history of hemorrhagic diathesis of thrombosis. The dysfibrinogenemia was discovered by chance in a routine laboratory preoperative screening which showed a prolonged thrombin time. Analyses of family members revealed the same abnormality in a daughter and grandson. No member of her family had a history of hemorrhagic diathesis or thrombosis.

The coagulation and fibrinolysis studies were as described elsewhere [3]. Fibrinogen purification was carried out as follows: $\mathrm{BaSO}_{4} 100 \mathrm{mg} / \mathrm{ml}$ of plasma was added; the mixture was stirred for $1 \mathrm{~h}$ and centrifuged for $15 \mathrm{~min}$. The supernatant was submitted to double precipitation with glycine at a concentration of $165 \mathrm{mg} / \mathrm{ml}$. The precipitate obtained was redissolved in the same volume of phosphate buffer $5 \mathrm{mmol} / 1, \mathrm{pH} 7.4$, containing epsilon aminocaproic acid (EACA) $0.1 \mathrm{~mol} / 1$. The solution was submitted to double precipitation with $\left(\mathrm{NH}_{4}\right)_{2} \mathrm{SO}_{4}$ at $26 \%$ saturation. The final precipitate was redissolved in the same phosphate, EACA buffer and dialyzed overnight against $\mathrm{NaCl} 0.3 \mathrm{~mol} / \mathrm{l}$. The coagulation index of the protein obtained ranged between 90-97\%. Plasminogen contamination of the fibrinogen preparation could not be detected using the chromogenic substrate S-2251 (Kabi Diagnostica, Stockholm, Sweden) following the 1-h incubation period.

Coagulation of patient's plasma was registered spectrophotometrically at $350 \mathrm{~nm}$ as described by Gruendlinger and Bouvier [4] using bovine thrombin (Diagnostic Reagents Ltd, Thame, Oxon, UK) $(1 \mathrm{NIH} / \mathrm{ml}$ final concentration) and reptilase (Pentapharm Ltd, Basle, Switzerland) $(1 \mathrm{BU} / \mathrm{ml})$ as inducing agents.

We studied the influence of propositus plasma on normal plasma thrombin time as described by Langen and Bithell [5], and the influence of $\mathrm{Ca}^{2+}$ ions on patient's plasma thrombin time.

\section{Studies of fibrin formation}

Fibrinopeptide release was studied by HPLC* and its kinetics by a modification of the TCA method [5]. Fibrin monomer aggregation was measured by the technique of Belitser et al. [6]. Fibrin stabilization was carried out according to Gralnick et al. [7] using patient's plasma instead of purified fibrinogen solution, after having assessed normal levels of F. XIII.

Fibrinogen proteolysis by plasmin was performed according to Denninger et al. [8]. Samples were studied by immunoelectrophoresis [9] and by SDS-PAGE [10] at different time intervals. 
Physicochemical studies of purified fibrinogen

Determination of the electrophoretic mobility of fibrinogen was performed in plasma and in purified fibrinogen by immunoelectrophoresis [9] and crossed immunoelectrophoresis [11] using two different batches of agarose (agarose A and C, Pharmacia Fine Chemicals) of different electroendosmosis. The mobility of the reduced forms of the three chains of normal and propositus fibrinogens was studied by SDS-PAGE (7.5\%) [10]. The sialic acid was measured by Aminoff's thiobarbituric acid method [12] and the hexosamine content, by the technique of Cessi and Piliego [13]. The sedimentation coefficient was determined as described elsewhere [2].

The heterogeneity of the purified fibrinogen for the patient was studied by three different techniques.

1. By isoelectric focussing (IEF) of non-reduced purified fibrinogen which was performed in a Pharmacia horizontal apparatus in 1.6-mm horizontal slabs of $1 \%$ agarose (IEF grade, Pharmacia Fine Chemicals, Uppsala, Sweden) containing 12\% (wt/vol) sorbitol, 5\% (vol/vol) ampholines 3-10 pH range (Ampholine ${ }^{\star}$, LKB Bromma, Sweden). A pre-electrophoresis was performed at $250 \mathrm{~V}$, for 3-4 h after which $25 \mu 1(20 \mu \mathrm{g})$ of the fibrinogen solution were applied near the cathode. Electrophoresis was continued overnight. Gels were fixed in 5\% sulphosalicylic acid plus $10 \%$ trichloroacetic acid for $30 \mathrm{~min}$, placed in a destaining solution of methanol:acetic acid:distilled water $(3: 1: 6)$ for $30 \mathrm{~min}$ and stained with Coomassie R-250 (Merck). The cathode solution used was $\mathrm{NaOH} 0.3 \mathrm{~mol} / 1$ and the anode solution $\mathrm{SO}_{4} \mathrm{H}_{2} 0.03 \mathrm{~mol} / \mathrm{l}$. A high $\mathrm{p} I$ calibration kit (Pharmacia Fine Chemicals, Uppsala, Sweden) was used as a control for the isoelectric points.

2. By chromatofocussing in a diethyl-aminoethyl cellulose matrix (DE 52 Whatman Ltd, Springfield Mill, UK) in columns of $0.9 \times 25 \mathrm{~cm}$. One $\mathrm{ml}$ of a fibrinogen solution $\left(A_{280}=0.5\right)$ was applied to the column, previously balanced with buffer imidazol $0.025 \mathrm{~mol} / 1, \mathrm{pH}: 7.4$. The chromatofocussing was run with polybuffer 74 (Pharmacia) adjusted at $\mathrm{pH}: 4$; flow rate was $25 \mathrm{ml} / \mathrm{h}$ and $3 \mathrm{ml}$ fractions were collected. In each of these the $\mathrm{pH}$ (Model 4500 Digital $\mathrm{pH}$ meter, Beckman Instruments, Fullerton, CA, USA) and fibrinogen content were determined [14].

3. Two-dimensional polyacrylamide gel electrophoresis was carried out essentially as described by Polack et al. [15]. In the first dimension, ampholines 3.5-10 (LKB) were used in $4 \%$ acrylamide gels rods $(0.25 \times 7 \mathrm{~cm})$ The second dimension was performed in homogeneous $10 \%$ acrylamide gels.

\section{Results}

Test of coagulation and fibrinolysis

The results are shown in Table I. The activated partial thromboplastin time, thrombin and reptilase times together with fibrinogen concentrations determined by methods depending on the rate of coagulation, were abnormal.

The spectrophotometric recording of coagulation in patient's plasma showed a delay at the onset of clot formation with both reagents. With reptilase, the slope and 
TABLE I

Coagulation tests of patient

\begin{tabular}{lcc}
\hline Test & Patient & Normal \\
\hline Protrombin time (s) & 12 & 12 \\
Activated partial thromboplastin time (s) & 56 & 40 \\
Thrombin time (s) & 38 & 18 \\
Reptilase time (s) & 41 & 18 \\
Factors II, V, VIII, IX, X, XI, XII, XIII (\%) & Normal & $80-130$ \\
Plasma fibrinogen levels (mg/di). & & \\
Thrombin clotting time & 49 & $200-400$ \\
Tyrosine content & 123 & $200-400$ \\
Heat precipitation & 150 & $150-300$ \\
Electroimmunoassay & 280 & $200-400$ \\
Single radial immunodiffusion & 280 & $200-400$ \\
Antithrombin III (mg/dl) & 33 & $30-50$ \\
Plasminogen (\$) & 110 & $70-130$ \\
Euglobulin lysis time (min) & 180 & 180 \\
\hline
\end{tabular}

final amplitude were similar to normal, whereas with thrombin, the slope was reduced and the final amplitude decreased (Fig. 1).

The addition of abnormal plasma to normal plasma did not inhibit the latter's thrombin time and the presence of calcium ions restored the abnormal plasma thrombin time (data not shown).
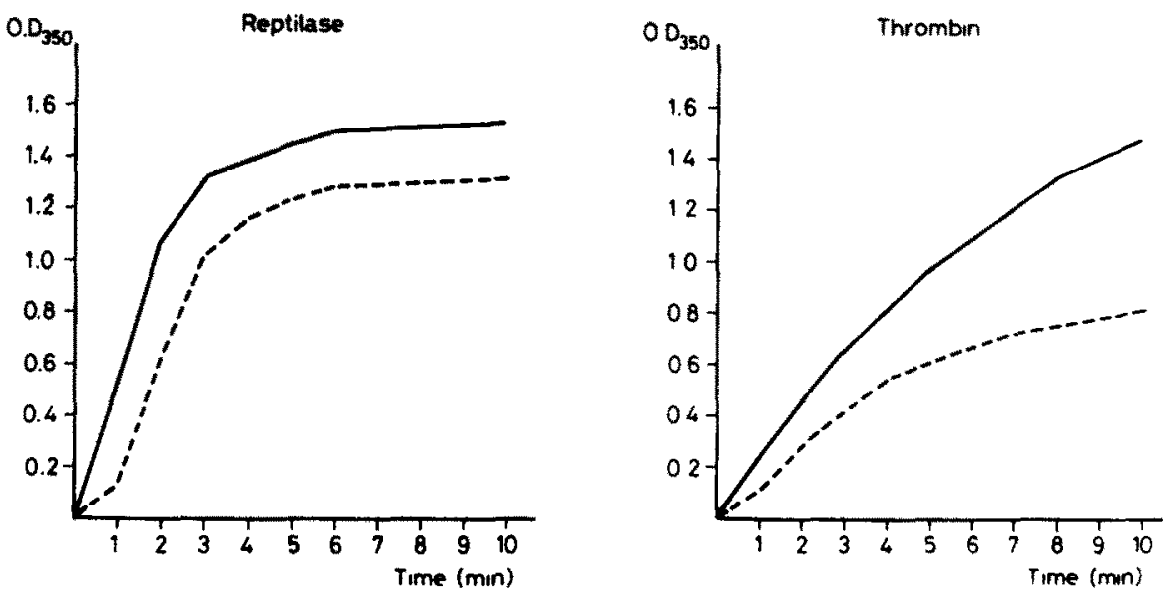

Fig. 1. Polymerization curves of the patient's plasma (-...-) and normal plasma $(-[-)$ after the addition of human thrombin $(1 \mathrm{NIH} / \mathrm{ml})$ and reptilase $(1 \mathrm{BU} / \mathrm{ml})$. 


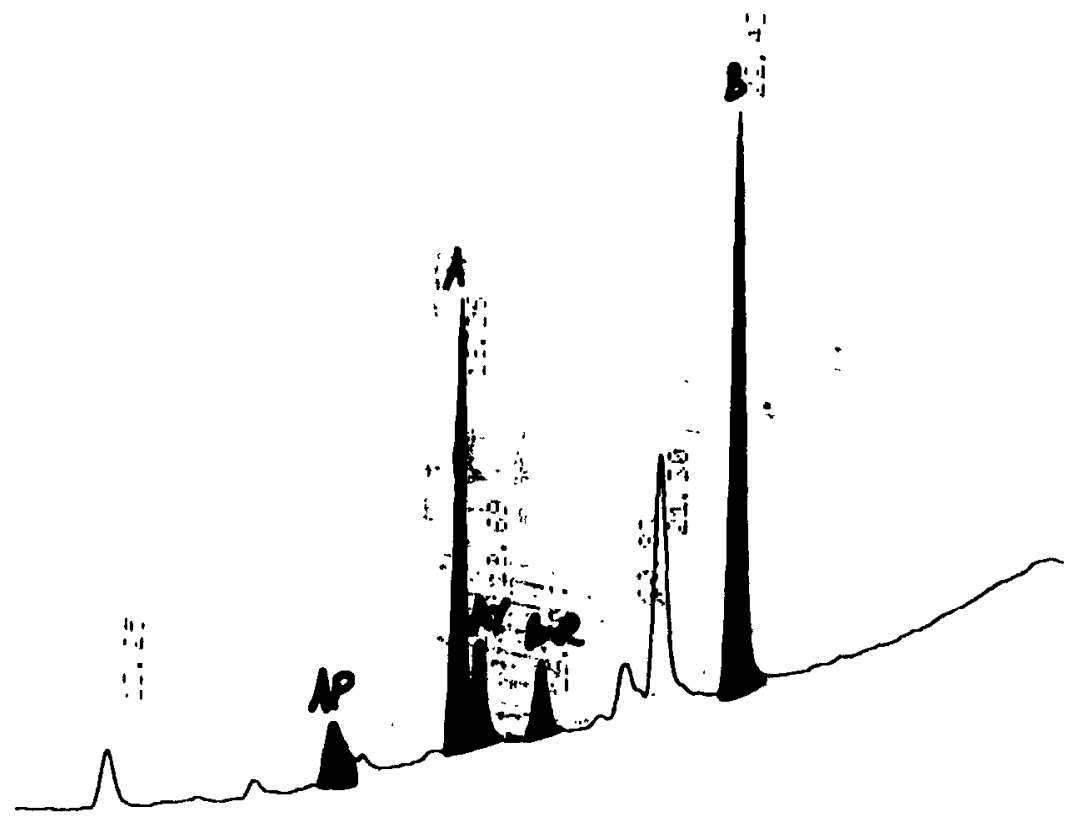

Fig. 2. HPLC profile of patient's fibrinopeptides released after prolonged thrombin action. The relation $\mathrm{FpA}: \mathrm{FpB}=0.84$ is closest to 1 , indicating no evidence of abnormal fibrinopeptides. AP, fibrinopeptide A phosphorylated; A, fibrinopeptide A; AY, Des-arg, fibrinopeptide A; B-R, Des-arg-fibrinopeptide B; B, fibrinopeptide B.

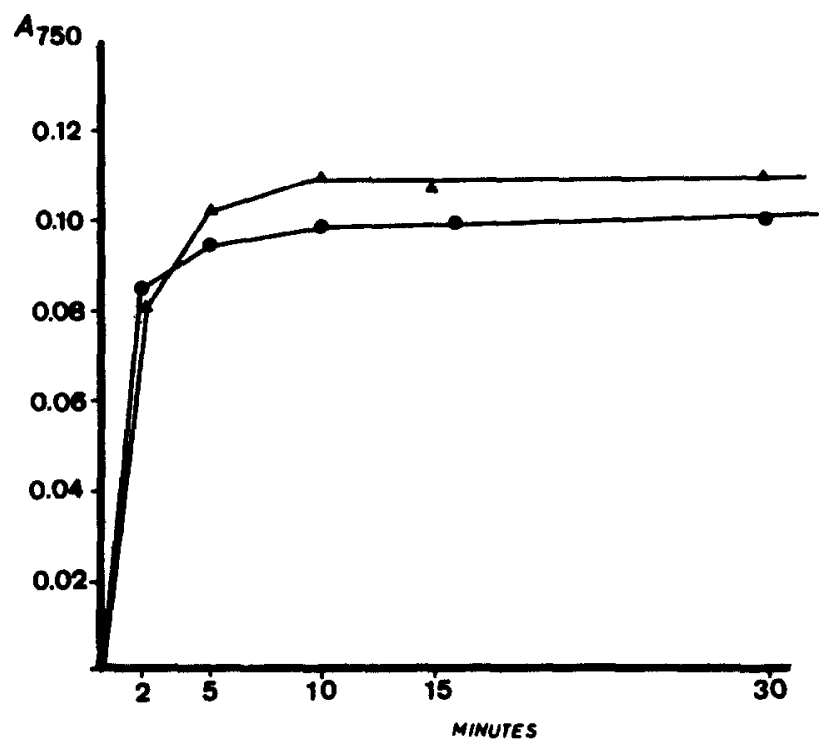

Fig. 3. Fibrinopeptide release. $\Delta$, Fibrinogen of propositus; $\bullet$, normal fibrinogen. Notice that the kinetics of fibrinopeptide release of patient's fibrinogen was similar to normal. 


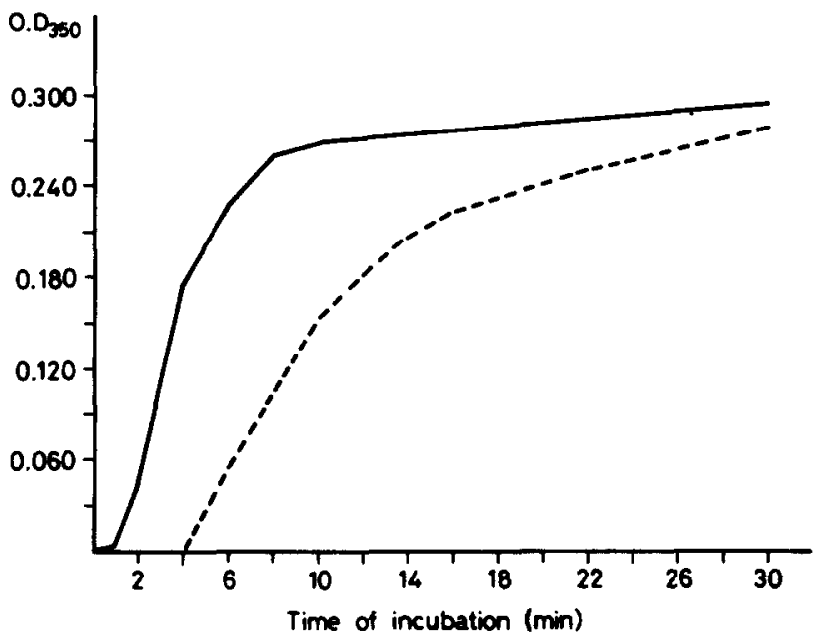

Fig. 4. Polymerization of performed normal (_- ) and patient (......) fibrin monomers in phosphate buffer $\mathrm{pH} 7.4$ at $25^{\circ} \mathrm{C}$.

\section{Studies of fibrin formation}

Release of fibrinopeptides after thrombin addition was similar for both normal and patient fibrinogens, either by the HPLC or the TCA method (Figs. 2 and 3).

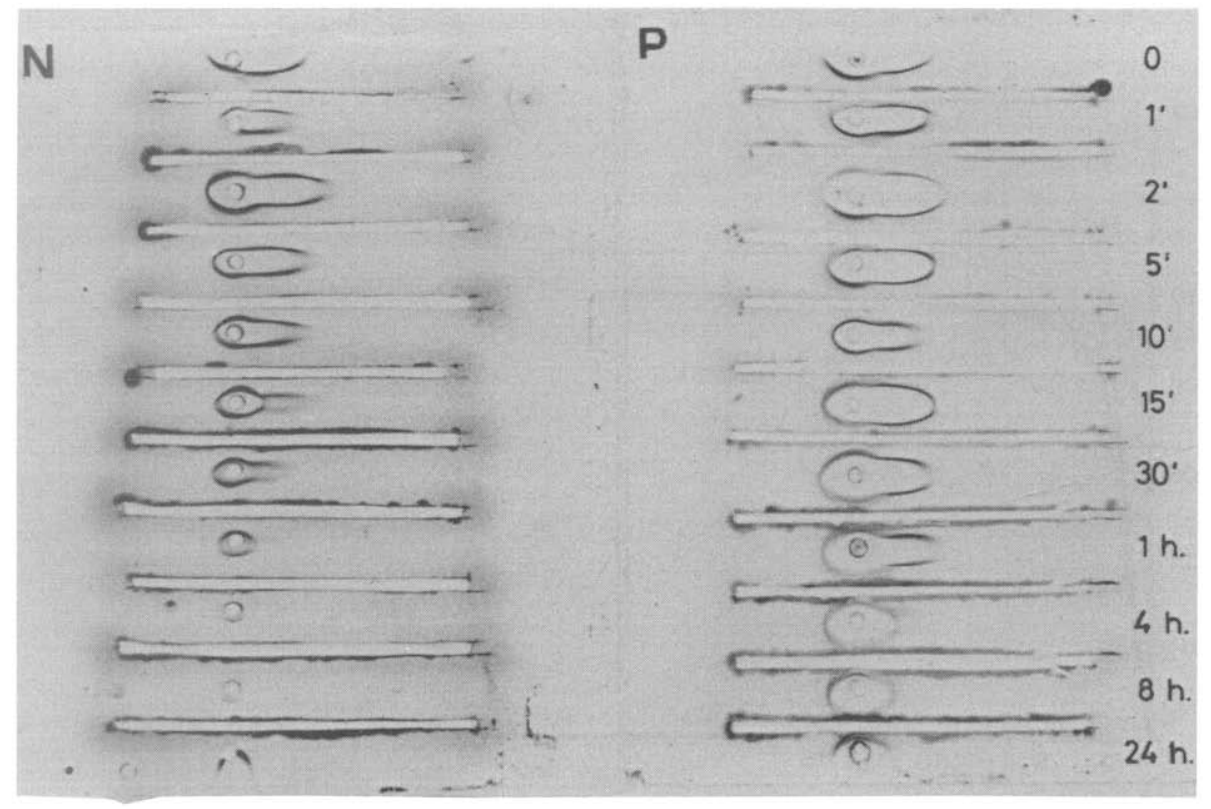

Fig. 5. Immunoelectrophoresis of sequential samples from plasmic digests. N, normal; P, propositus. Antisera in troughs is anti-human fibrinogen. 


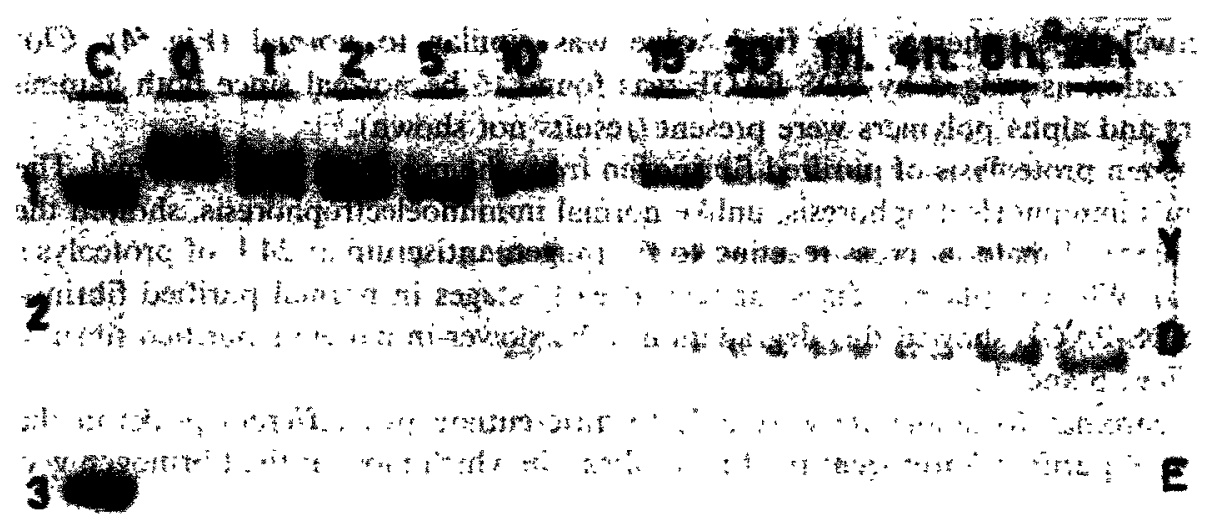

\section{$\underline{N}$}

Fig. 6. SDS-polyacrylamide gel electrophoresis of normal, non-reduced sequential samples from plasmic digest. 1, Katalase (mol wt 240000); 2, aldolase (mol wt 158000); 3, albumin (mol wt 45000).

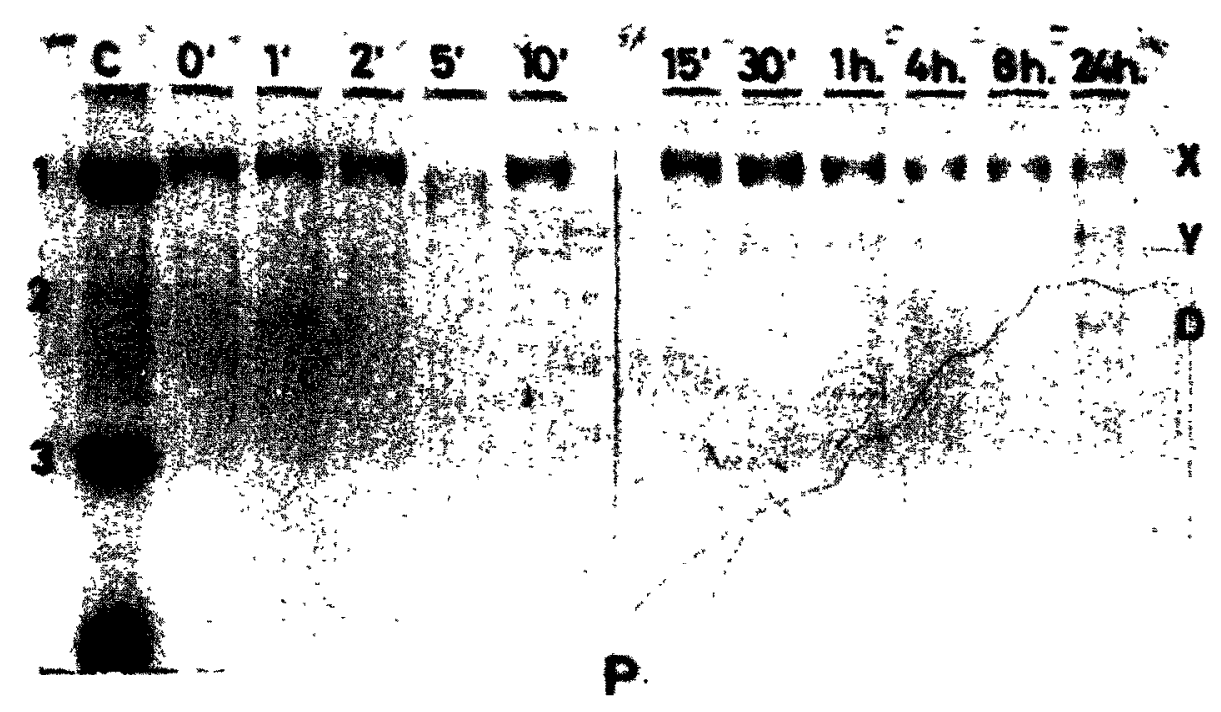

Fig. 7. SDS-polyacrylamide gel electrophoresis of patient, non reduce sequential samples from plasmic digest. 1, 2 and 3 are the same molecular weight markers pointed out in Fig. 4. 
The aggregation of fibrin monomers showed a prolonged latency time with a defective slope, whereas the final value was similar to normal (Fig. 4). Clot stabilization as judged by SDS-PAGE was found to be normal since both gamma dimers and alpha polymers were present (results not shown).

Plasmin proteolysis of purified fibrinogen from the proposita was abnormal. The patient's immunoelectrophoresis, unlike normal immunoelectrophoresis, showed the persistence of material cross reacting to fibrinogen antiserum at $24 \mathrm{~h}$ of proteolysis (Fig. 5). Whereas plasmic digest appear at early stages in normal purified fibrinogen, SDS-PAGE showed this degradation to be slower in patient's purified fibrinogen (Figs. 6 and 7).

By chromatofocussing we were able to differentiate two different peaks in the elution of purified fibrinogen: the first of these, in which most of the fibrinogen was
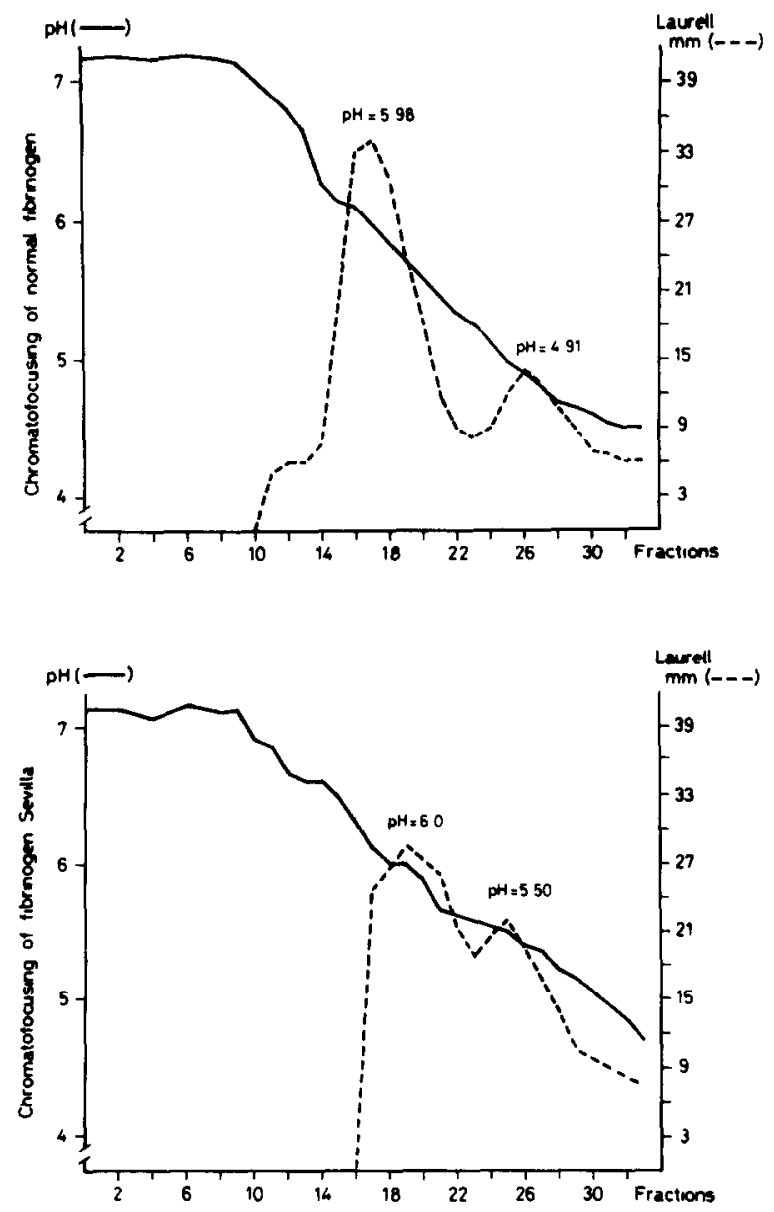

Fig. 8. Chromatofocussing of normal and patient's fibrinogen. Notice the difference in pH between the two second elution peaks. 
present, eluted at a $\mathrm{pH}$ between 6.05-5.90; and the second peak which elutes a $\mathrm{pH}$ between 4.9-5.07. The patients fibrinogen shows an abnormality in pattern elution with its second peak eluting at a pH slightly more basic than normal (pH: 5.5) (Fig. 8).

\section{Isoelectrofocussing in agarose gel}

The isolated purified fibrinogen presented a heterogeneity with the presence of various bands showing isoelectric points between $\mathrm{p} I$ 5.20-6.55. Although both the patient's and normal fibrinogen were spread over the same interval of $\mathrm{p} I$, there were qualitative differences in both fibrinogens. Between these heterogenous bands, we can differentiate two groups, one of them focussing at $\mathrm{p} I 5.20-5.85$ and the other at $\mathrm{p} I$ 5.85-6.55. In the first group (more acid) we can observe in the patient's fibrinogen a more cathodic band in comparison with the normal fibrinogen. In the second group (more basic) there is an almost complete absence of the extreme cathodic band in the patient's fibrinogen (Fig. 9).

Two dimensional electrophoresis of reduced fibrinogen revealed two main $\gamma$ and three B $\beta$ chains and several weakly stained A $\alpha$ chains (Fig. 10). The pattern was

\section{N P pl}

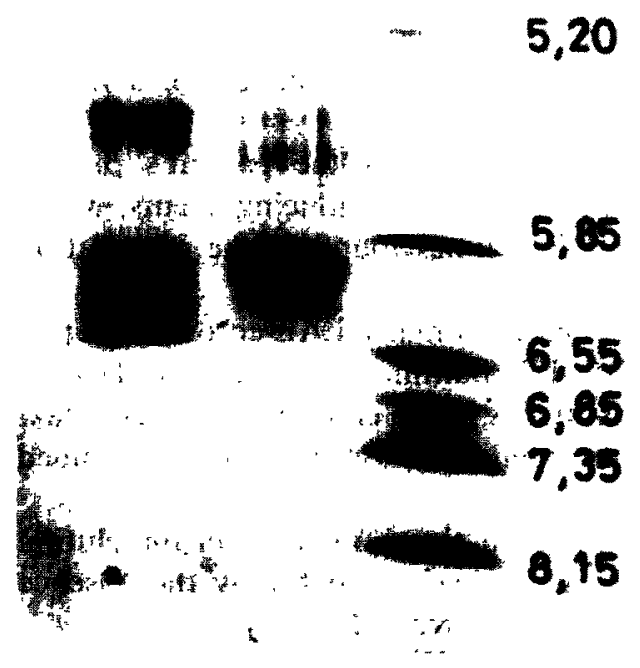

Fig. 9. Isoelectrofocussing in agarose gel of normal $(\mathrm{N})$ and patient's (P) fibrinogens. $\mathrm{p} I$, protein isoelectric point markers. (See test.) 


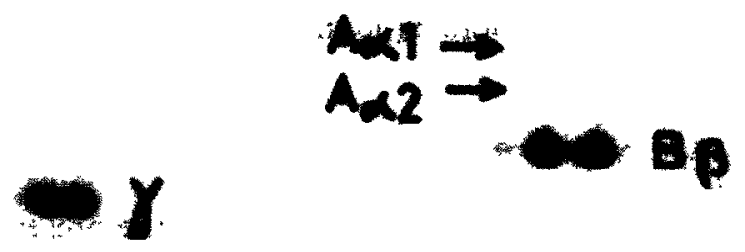

Fig. 10. Two-dimensional electrophoresis of reduce patient fibrinogen. (See text.)

similar to that shown by the reduced normal fibrinogen and to that described by other authors $[15,16]$.

\section{Physicochemical characteristics}

We found that the patient's fibrinogen had sialic acid and hexosamine contents within normal limits, similar to normal fibrinogen. Its sedimentation coefficient was $S_{20 . \mathrm{w}}=8.20(n: 8.20)$. The patient's fibrinogen showed total antigenic community with the control. The electrophoretic mobility studied by SDS-PAGE in both reduced and non-reduced fibrinogen was normal and their were no differences in its mobility when studied by immunoelectrophoresis and crossed immunoelectrophoresis (in both plasma and purified fibrinogen).

\section{Discussion}

The results demonstrated the existence of an abnormal fibrinogen in a family with probable autosomal dominant inheritance.

The spectrophotometric analysis of the coagulation of the patient's plasma showed a delay when thrombin and reptilase were used as inducing agents, which agrees with the prolonged thrombin and reptilase times found in the coagulation studies of the plasma of the proposita.

In six of the reported dysfibrinogenemias, an abnormal DEAE-chromatography is described [2]. In fibrinogens Bethesda III [17], Baltimore I [18], Paris II [19], Nancy [20] and Philadelphia [2], the abnormality lies in the elution of the first peak, whereas in Paris I [22], the two fibrinogen peaks emerged later than their presumed counterparts.

Mosesson and Finlayson [23] have indicated that the differences in the elution characteristics of peaks 1 and 2 fibrinogen can be accounted for by the absence (peak 1) or the presence (peak 2) of a $\gamma$-chain variant termed $\gamma^{\prime}$.

By two-dimensional electrophoresis, we were unable to find any abnormality in the $\gamma$-chain of the patient's fibrinogen. Nevertheless, the patient's purified fibrinogen showed an abnormal distribution in its focussed bands, especially in the group 
which focussed on the $\mathrm{p} I$ interval of 5.20-5.85. This abnormality could explain the existence, in the experience of chromatofocussing, of a peak which elutes at $\mathrm{pH} 5.5$ slightly more basic than the normal peak ( $\mathrm{pH} \mathrm{4.90).}$

Our fibrinogen showed a delayed plasmin degradation with the persistence of high molecular weight components. Similar abnormality is described in fibrinogens Bethesda III [17], Chapel Hill III [24] and Tokyo I [25]. The first of these dysfibrinogenemias had clinical symptoms, and the latter two had an anodic mobility demonstrated by immunoelectrophoresis and decreased levels of plasma Factor XIII. The existence, in our case, of abnormal classes of fibrinogen, could be responsible for an abnormal binding of plasmin to fibrinogen.

On the other hand, the presence of these abnormal molecules of fibrinogen could interact with the polymerization sites and could be responsible for both the delayed rate of clotting, especially when low concentrations of thrombin were used, and the abnormal polymerization of fibrin monomers.

We believe that this abnormal fibrinogen should be tentatively designated 'fibrinogen Sevilla' even though more extensive biochemical studies are needed to establish whether the fibrinogen present in this kindred is unique.

\section{Acknowledgements}

The HPLC determination of fibrinopeptide release was kindly performed by Dr. David Lane at Charing Cross and Westminster Medical School, University of London, London, UK.

\section{References}

1 Menache D. Constitutional and familial abnormal fibrinogen. Thromb Diathes Haemorrh 1964; Suppl 13:173-185.

2 Rocha E, Păramo JA, Aranda A, Cuesta B, Fernăndez J. Congerital dysfibrinogenemias. A review. Ric Clin Lab 1985;15:205-229.

3 Rocha E, Lasierra J, Narvaiza MJ, Vilades E, Palacios E, Fernández J. Fibrinogen logroño. A new case of congenital dysfibrinogenemia. Ric Cin Lab 1984;14:663-672.

4 Gruendinger $\mathrm{BJ}$. Bouvier $\mathrm{CA}$. Applications d’ane méthode photometrique à létude des phénomenes de coagulation et de tibrinolyse. Thromb Diathes Haemorm 1964;12:425-451.

5 Langen RH, Bithell TC. Hereditary dysfibrinogenemia characterized by slow fibrinopeptide release and competitive inhibition of thrombin. Acta Haematol 1984;71:150-157.

6 Belitser VA, Varetskaja TV, Malneva GV. Fibrinogen-fibrin interaction. Biochim Biophys Acta $1968 ; 154: 367-375$.

7 Grainick HR, Coller BS, Fratantoni JC, Martinez J. Fibrinogen Bethesda III: a hypodysfibrinogenemia. Blood 1979;53:28 -46.

8 Denninger MH, Finlayson JS, Reamer LA, Parquet-Gernez A, Goudemand M, Menaché D. Congenital dysfibrinogenemia: fibrinogen Lille. Thromb Res 1978;13;453-466.

9 Grabar P, Willams CA. Méthode permettant l'étude conjuguée des propiétés eléctrophoretiques et immunochimiques d'un mélange des proteines. Applications an serum sanguin. Biochim Biophys Acta 1953;10:193-194.

10 Weber K, Osborn M. The reliability of molecular weight determinations by dodecylsulfate poly w acrylamide gel electrophoresis. J Biol Chem 1969;224:4406-4412. 
11 Clarke HGM, Freeman TA. A quantitative immunoelectrophoresis method. Protides Biol Fluids Proc Collog 1967;14:503-509.

12 Aminoff $\mathrm{D}$. Methods for the quantitative estimation of $\mathrm{N}$-acetylneuraminic acid and their application to hydrolysates of sialomucoids. Biochem J 1961;81:384-392.

13 Cessi C, Piliego F. The determination of amino sugar in the presence of aminoacids and glucose. Biochem J 1960;77:508-510.

14 Laurell CB. Quantitative estimation of proteins by electrophoresis in agarose gel containing antibodies. Anal Biochem 1966;15:45-52.

15 Polack B, Valiron O, Concord E, Freyssinet JM, Hudry-Clergeon G. Molecular characterization of an abnormal fibrinogen by two dimensional electrophoresis. Clin Chem 1984;30:2093-2097.

16 Kuyas C, Haeberli A, Straub PW. Sialic acid-dependent polypeptide chain heterogenity of human fibrinogen demonstrated by two-dimensional electrophoresis. Thromb Haemostas 1982;47:19-21.

17 Gralnick HR, Coller BS, Fratantoni JC, Martinez J. Fibrinogen Bethesda III. A hypodysfibrinogenemia. Blood 1979;53:28-46.

18 Beck EA, Shainoff JR, Vogel A, Jackson DP. Functional evaluation of an inherited abnormal fibrinogen: fibrinogen Baltimore. J Clin Invest 1975;55:1190-1194.

19 Samama M, Soria J, Soria C, Bousser J. Dysfibrinogénémie congénitale et familiale sans tendence hemorragique. Nouv Rev Fran Hematol 1969;9:817-832.

20 Streiff F, Alexandre P, Vigueron C, Soria J, Soria C, Mester L. Un nouveau cas d'anomalie constitutionnelle et familiale del fibrinogene sans diathesis hemorragique. Thromb Diathes Haemorrh 1971;26:565-576.

21 Martinez J, Holburu RR, Shapiro SS, Ersley AJ. A hereditary hypodysfibrinogenemia characterized by fibrinogen hypercatabolism. J Clin Invest 1974;53:600-611.

22 Mosesson MW, Amrani DL, Menaché D. Studies on the structural abnormality of fibrinogen Paris I. J Clin Invest 1976;57:782-790.

23 Mosesson MW, Finlayson JS, Unifleet RA. Human Fibrinogen heterogenities. III Identification of $\gamma$ chain variants. J Biol Chem 1972;247:5223-5227.

24 Carrell N, Gabriel DA, Blatt PM, Carr ME, McDonagh J. Hereditary dysfibrinogenemia in a patient with thrombotic disease. Blood 1983;62:439-447.

25 Samori T, Jatabe M, Ukita M, Fijimaki M, Fujutake K. A new type of congenital dysfibrinogenemia (fibrinogen Tokyo) with defective stabilization of fibrin polymer. Thromb Diathes Haemorrh 1975;34:329 (abst.). 